The Editorial Board would like to encourage the submission to the Advances of Review Papers summarising and coordinating recent results in any of the fields of Applied Probability.

In addition to these Review Papers, Advances is also designed to be a medium of publication for (1) longer research papers in Applied Probability, which may include expository material, (2) expository papers on branches of mathematics of interest to probabilists, (3) papers outlining areas in the biological, physical, social and technological sciences in which probability models can be usefully developed, and finally, (4) papers in Applied Probability presented at conferences which do not publish their proceedings.

In short, the main function of Advances is to define areas of recent progress and potential development in Applied Probability. As with the Journal of Applied Probability, Advances undertakes to publish papers accepted by the Editors within 15 months of their submission.

The Editorial Board consists of E. Sparre Andersen, D. Blackwell, V. R. Cane, J. W. Cohen, B. Gnedenko, J. Hájek, E. J. Hannan, C. C. Heyde, J. Keilson, D. G. Kendall, J. F. C. Kingman, K. Krickeberg, R. M. Loynes, P. A. P. Moran, J. Neveu, K. R. Parthasarathy, N. U. Prabhu, R. Pyke, C. A. B. Smith and L. Takács. The Editor-in-Chief is J. Gani, and the Editorial Office of the Advances is in the Department of Probability and Statistics, The University, Sheffield S3 7RH, England.

Volume 6 No. 2 of Advances contains the following papers:

Third conference on stochastic processes and their applications
C. Cannings
The latent roots of certain Markov chains arising in genetics: A new
R. Fildes
T. Lindvall approach, I. Haploid models
An age dependent branching process with variable lifetime distribution: The generation size
A. Agresti
M. S. Bartlett Limit theorems for some functionals of critical Galton-Watson branching processes
M. Dwass
Bounds on the extinction time distribution of a branching process
J. J. Hunter
The statistical analysis of spatial pattern
Poisson process and distribution-free statistics, I
S. I. Resnick
Renewal theory in two dimensions: Basic results
Inverses of extremal processes

Subscription rates (post free) per volume are:

For libraries and institutions:

For individuals belonging to a

recognised scientific society

\begin{tabular}{|c|c|c|}
\hline U.S.\$39.00 & fstg. 15.00 & $\$ A .30 .00$ \\
\hline U.S.\$13.00 & fstg. 5.00 & $\$ \mathrm{~A} .10 .00$ \\
\hline U.S. $\$ 24.70$ & fstg. $\quad 9.50$ & $\$ A .19 .00$ \\
\hline U.S. $\$ 36.40$ & fstg. 14.00 & $\$ A .28 .00$ \\
\hline
\end{tabular}

The prices of back issues

per volume are:

Volume 1 to 4 (1969-72)

Volume 5 (1973)

U.S. $\$ 36.40$ fstg. 14.00

$\$ A .28 .00$

A special discount of $10 \%$ is allowed to subscribers who order current issues of both the Journal and Advances at the same time direct from the Editorial Office. In this case the combined prices will be as follows:

$\begin{array}{llll}\text { For libraries and institutions: } & \text { U.S. } \$ 70.20 & £ \text { stg.27.00 } & \$ \mathrm{~A} .54 .00 \\ \text { For individuals: } & \text { U.S. } \$ 23.40 & £ \text { stg. } 9.00 & \$ \mathrm{~A} .18 .00\end{array}$

Cheques made out on U.S., U.K. and Australian banks will be acceptable: they should be made payable to Applied Probability, and sent to:

Executive Editor, Advances in Applied Probability,

Department of Probability and Statistics,

The University, Sheffield S3 7RH, England. 


\section{Mathematical Spectrum}

A Magazine of Contemporary Mathematics

This magazine addresses itself primarily to young mathematicians in schools, colleges of education, and universities. Its object is to discuss the entire range of modern mathematical disciplines (pure mathematics, applied mathematics, statistics, operational research, computing science, biomathematics) in an informative but informal manner and to relate discoveries in mathematics to progress in the natural sciences, technology, social studies, and business management.

The Editors believe that the process of learning is a dialogue, and consequently they wish to promote active participation by readers. Correspondence on any subject relating to mathematics and mathematical education is welcomed. There is also a problem section, and readers are encouraged to submit their solutions, the best of which are published.

Volume $6(1973 / 74)$ includes the following articles.

In Number 1: David Blow The numerical analysis of a simple game

T. P. Speed Statistics in school and society

Ramesh Kapadia How rigorous can a proof be?

Richard Rado How the lion tamer was saved

J. D. Murray Approximate methods in mathematics

In Number 2: Underwood Dudley Who was the first-non-Euclidean?

Joan Holland

A matrix method for solving cubic equations sumerically

Pat Rogers The continuum hypothesis

D. K. Ross and A new look at the S. H. M. equation

E. F. Carter

A. Sackheld and A non-linear differential equation arising M. G. Frost in relativity theory

For further information application should be made to

Editor - Mathematical Spectrum, Hicks Building,

The University, Sheffield S3 7RH, England.

Mathematical Spectrum is published by the Applied Probability Trust. 


\section{Methuen's Supplementary Review Series in Applied Probability}

General Editor: M. S. BARTLETT, M. A., D.SC., F. R. S.

Editor: J. GANI, D. I. C., PH. D., D.SC.

The remaining stock in this Series has been purchased by the Applied Probability Trust. The volumes still available are:

Volume 2. DIFFUSION MODELS IN POPULATION GENETICS by M. Kimura

Volume 3. GROUP REPRESENTATIONS AND APPLIED PROBABILITY by E. J. Hannan

Volume 5. RECENT RESULTS IN INFORMATION THEORY by S. Kotz

Volume 6. ON THE ALGEBRA OF QUEUES by J. F. C. Kingman

Volume 8. STOCHASTIC APPROACH TO CHEMICAL KINETICS by D. A. McQuarrie

While stocks last, these reviews may be purchased at the price of $£ 0.50$ (U.S. $\$ 1.25$; $\$ A .1 .00$ ) each, post free, or $£ 2.00$ (U.S. $\$ 5.00$; $\$ A .4 .00$ ) for the five volumes. Please send your order to:

Executive Editor, Applied Probability,

Department of Probability and Statistics,

The University, Sheffield S3 7RH, England.

Also available: Proceedings of the WHO SYMPOSIUM ON QUANTITATIVE EPIDEMIOLOGY (Moscow, November 1970); reprinted from the Advances in Applied Probability, Vol. 3. The price per copy is $£ 0.50$ (U.S. \$1.25; \$A. 1.00).

It is essential that all orders are accompanied by a remittance, payable to "Applied Probability". 


\section{Subscription rates}

Subscriptions (post free) for the 1974 volume of the Journal are:

U.S. $\$ 39.00$, fstg. 15.00 , \$A.30.00, for libraries and institutions;

U S. $\$ 13.00$, fstg. 5.00,\$A.10.00, for individuals belonging to a recognised scientific society. Members of the London Mathematical Society should apply direct to the Secretary of the Society for copies of the Journal.

All enquiries about the Journal, as well as other subscriptions and orders for back numbers should be sent to the Executive Editor, Miss M. Hitchcock, Department of Probability and Statistics, The University, Sheffield S3 7RH, England. The price of back numbers varies from volume to volume, and enquiries should be sent to the Executive Editor. Cheques, money orders, etc. should be made out to Applied Probability; cheques on U.S., U.K. and Australian banks will be acceptable.

\section{Notes for Contributors}

It is a condition of publication in the Journal of Applied Probability that papers shall not previously have appeared elsewhere, and will not be reprinted without the written permission of the Trust. The copyright of all published papers shall be vested in the Trust. It is the general policy of the Journal not to accept for publication papers which cannot appear in print within 15 months of their date of submission. Authors will receive 50 reprints of their papers free, and joint authors a proportional share of this number. Additional reprints will be provided at cost.

Manuscripts should be written in English or French; manuscripts in other languages may be accepted by the Editors, but will appear (subject to the author's agreement) in English or French translation in the Journal.

It will be of help to the Editors if the following conventions are adopted:

a) The manuscript should be typewritten, using double spacing, on one side of the paper only. The original and a copy may be submitted to any Editor; a duplicate of the covering letter should, however, be sent to the Editor-in-Chief.

b) Each paper submitted should be accompanied by

(i) a short abstract of approximately 4-10 lines giving a non-mathematical description of the subject matter and results;

(ii) a list of keywords detailing the contents for the purpose of computerised information retrieval.

c) References should be indicated in the text by the name of the author(s) and the date, thus: Feller (1961), and the full references listed at the end of the article in alphabetical order. Journal references should include the title of the article cited, the title of the journal (abbreviated in the style of the International Journal of Abstracts: Statistical Theory and Method), the volume, and inclusive page numbers. Book references should give the full title, the publisher, and the place of publication. For example:

Feller, W. (1961) A simple proof of renewal theorems. Comm. Pure Appl. Math. 14, 285-293.

Robinson, E. A. (1959) An Introduction to Infinitely Many Variates. Griffin, London

d) Type faces should be carefully distinguished on the manuscript using the following standard methods of marking:

Italic capitals $(T, I, R)$ and lower case letters $(t, i, r)$ should be underlined once, e.g., $\underline{T}, \underline{I}, \underline{R}, \underline{t}, \underline{i}, \underline{r}$.

Bold-face capitals $(T, I, R)$ and lower case letters $(t, i, r)$ should have a curly underline, e.g., T, $\mathbf{I}, \underset{\sim}{\mathbf{R},}, \underline{\mathbf{t}}, \underset{\sim}{\mathbf{r}}$.

Greek characters $(\alpha, \beta, \theta)$ and script letters $(\mathscr{J}, \mathscr{I}, \mathscr{R})$ should be carefully drawn and identified when first used by a marginal note of the form ' $\alpha$-lower case Greek alpha' or ' $\mathscr{R}$-script R'.

e) Indices and subscripts should be clearly distinguished, using the marking $\underset{\sim}{4}, \frac{1}{4}$ where necessary.

Authors will receive only first proofs for correction; charges will be made for excessive alteration to these.

Printed in Israel at the Jerusalem Academic Press, P.O.B. 2390, Jerusalem. 


\section{CONTENTS}

NORMAN KAPLAN

W. A. O'N. WAUGH

W. A. O'N. WAUGH

J. C. GITTINS

SHÖICHI NISHIMURA

PETER J. COOKE

NORMAN STARR

N. U. AHMED AND K. L. TEO

VALERIE ISHAM

HANS D. UNKELBACH AND HELMUT WEGMANN

H. G. HERBERT

BENT NATVIG

DOUGLAS P. KENNEDY

SAMUEL LITWIN

B. F. LOGAN AND L. A. SHEPP

MARC MOORE

P. WHITTLE AND J. RUDGE

JAN-ERIK KARLSSON

H. CALLAERT

B. J. N. BLIGHT AND

J. L. DEVORE

K. C. CHANDA

MATTHEW GOLDSTEIN

JOSEPH B. KADANE

SHELDON M. ROSS

\section{Research Papers}

225 Multidimensional age-dependent branching processes allowing immigration: The limiting distribution

237 Modes of growth of counting processes with increasing arrival rates

248 Asymptotic growth of a class of size-and-agedependent birth processes

255 Resource allocation in speculative chemical research

266 Random collision processes and their limiting distribution using the discrimination information

281 Bounds for coverage probabilities with applications to sequential coverage problems

294 Optimal and adaptive stopping based on capture times

302 Optimal feedback control of stochastic McShane differential systems

310 The effect of intermittent exposure to risk on failure time distributions

320 The number of meetings in free Poisson traffic

332 Some approximate results for storage systems with continuous inputs

345 On the transient state probabilities for a queueing model where potential customers are discouraged by queue length

355 Limiting diffusions for the conditioned $M / G / 1$ queue

\section{Short Communications}

363 The distribution of the shortest distance between random cuts on opposite strands of DNA

369 A birth and death model of neuron firing

374 Anisotropically random mosaics

377 The optimal linear solution of a symmetric team control problem

382 A stochastic model for time lag in reporting of claims

388 Geometric and exponential decay in derived Markov chains

394 The recursive estimation of a Markov chain

401 Strong mixing properties of linear stochastic processes

409 Some inequalities on variances

413 A characterization of triangular arrays which are expectations of order statistics

417 Bounds on the delay distribution in $G I / G / 1$ queues 